\title{
DÉCADA DA ONU DA EDUCAÇÃO PARA O DESENVOLVIMENTO SUSTENTÁVEL O DITO E O NÃO DITO NO CAMINHO DE MUDANÇAS
}

Nilo Sérgio de Melo Diniz ${ }^{1}$

\begin{abstract}
Resumo
A Conferência Unesco da Década da Educação para o Desenvolvimento Sustentável (20052014), realizada, em 2014, no Japão, com governos, ONGs e universidades de 150 países, precedida por dois relatórios da Unesco (2012 e 2014), impressiona pela amplitude e diversidade de experiências. Entretanto, os relatórios parecem apenas tangenciar questões fundamentais. O foco numa educação para o Desenvolvimento Sustentável (DS), sem enfrentar controvérsias em torno do DS ou considerar o conceito de Educação Ambiental da própria Unesco, lançado na Conferência de Tbilisi (1977), deixa em aberto questões pertinentes à mudança na maneira de pensar e de agir. Apresentar algumas dessas questões, ausentes nesse processo, em contraste com ações e ideias em curso, incluindo a Encíclica Laudato $\mathrm{Si}$, é o que se pretende com este breve artigo, tendo o pressuposto de que um futuro verdadeiramente sustentável não pode prescindir de temas controversos e desconcertantes ao atual status quo econômico e político.
\end{abstract}

Palavras-chave: Educação ambiental. Desenvolvimento sustentável. Sustentabilidade.

\section{THE UN DECADE OF EDUCATION FOR SUSTAINABLE DEVELOPMENT SAID AND UNSAID IN THE WAY OF CHANGES}

\begin{abstract}
The UNESCO Conference of Decade of Education for Sustainable Development (2005-2014), held in 2014 in Japan, with governments, NGOs and universities from 150 countries, preceded by two UNESCO reports (2012 and 2014), surprising by coverage and diversity of experiences. However, the reports seem pass off key issues. The focus on education for sustainable development (SD), without facing controversies surrounding the DS or consider the concept of Environmental Education of UNESCO, launched at the Tbilisi Conference (1977), omits issues related to the change in thinking and acting. Presenting some of these issues absent in this process, in contrast to existing actions and ideas, including the Encyclical Laudato $\mathrm{Si}$, it is what is intended with this brief article, with the assumption that a truly sustainable future can not do without controversial issues to the current economic and political status quo.
\end{abstract}

Keywords: Environmental education. Sustainable development. Sustainability.

\footnotetext{
1 Sociólogo (ESP-SP), mestre em Comunicação/Jornalismo (UnB), especialização em Participação Social (UFMG) e Psicologia Junguiana (FACIS/IJEP) Consultor e ex-diretor de Educação Ambiental e do CONAMA (Ministério do Meio Ambiente).
} 


\section{DECENIO INTERNACIONAL SOBRE EDUCACIÓN PARA EL DESARROLLO SOSTENIBLE DE LA ONU LO DICHO Y LO NO DICHO EN EL CAMINO DE LAS TRANSFORMACIONES}

\section{Resumen}

La Conferencia de la UNESCO de la Década de la Educación para el Desarrollo Sostenible (2005-2014), que se celebró en 2014, en Japón, reuniendo gobiernos, organizaciones de la sociedad civil y universidades de 150 países, precedida por dos informes de la UNESCO (2012 y 2014), impresiona por la amplitud y la diversidad de la experiencia. Sin embargo, los informes parecen abordar superficialmente cuestiones fundamentales. El eje en la educación para el desarrollo sostenible (DS), sin hacer frente a controversias en torno a la DS o considerar el concepto de Educación Ambiental de la propia UNESCO, presentado en la Conferencia de Tbilisi (1977), deja abiertas cuestiones relacionadas con el cambio en el pensamiento y las maneras de actuar. Presentar algunas de estas cuestiones, ausente en este proceso, en contraste con las acciones e ideas existentes, incluyendo la Encíclica Laudato Si, es lo que se pretende con este breve artículo, con la suposición de que un futuro verdaderamente sostenible no puede prescindir de temas controvertidos y desconcertantes al actual status quo económico y político.

Palabras-clave: Educación ambiental. Desarrollo sustentable. Sostenibilidad.

\section{Introdução}

Não se pode resolver os problemas utilizando o mesmo tipo de pensamento que usamos quando os criamos. Albert Einstein

O senhor não daria banho a um leproso nem por um milhão de dólares?

Eu também não. Só por amor se pode dar banho a um leproso.

Madre Teresa de Calcutá

Aprender hoje para um futuro sustentável foi o tema da Conferência Mundial da Unesco sobre a Educação para o Desenvolvimento Sustentável - EDS, que avaliou o movimento internacional estimulado e, muitas vezes, apoiado pela Unesco, sob o título Década da Educação para o Desenvolvimento Sustentável (2005-2014). Os debates e as experiências apresentadas na referida conferência, que reuniu cerca de mil pessoas, em novembro de 2014, na cidade de Nagoya, Japão, realmente impressionam por sua diversidade e amplitude. Eram representantes de ministérios de Estados-membros da Unesco, de ONGs, universidades, empresas e de agências da ONU, além de especialistas e jovens de 150 países, que conheceram e discutiram inúmeras iniciativas de educação desenvolvidas no mundo, nessa década.

Os enunciados apresentados em relatórios da ONU parecem apenas tangenciar, ou mesmo olvidar, questões que, muito provavelmente, foram abordadas por algumas daquelas ações locais, sem que tenham sido, necessariamente, relatadas em suas páginas. Apresentar algumas dessas questões é o que se pretende neste breve artigo, com o propósito apenas de animar um diálogo, com base no pressuposto de que um futuro verdadeiramente sustentável não pode prescindir do exame de temas controversos e mesmo desconcertantes ao atual status quo.

A Declaração de Aichi-Nagoya, ao final dessa Conferência Mundial da Unesco, afirma que os seus participantes 
[...] adopt this Declaration and call for urgent action to further strengthen and scale up Education for Sustainable Development (ESD), in order to enable current generations to meet their needs while allowing future generations to meet their own, with a balanced and integrated approach regarding the economic, social and environmental dimensions of sustainable development. This Declaration recognises that people are at the centre of sustainable development and builds on the achievements of the United Nations (UN) Decade of ESD (2005-2014) ${ }^{2}$ (UNESCO, 2014, p.1).

O Relatório da Unesco, de 2012, sobre a Década da Educação para o Desenvolvimento Sustentável (DEDS), define como uma "educación para una transformación social conducente a la formación de sociedades más sostenibles", destacando quatro prismas de concepção da EDS. O primeiro seria integrador, com característica holística, ecológica, ambiental, econômica e sociocultural, desde o plano local, regional e mundial, em tempo passado, presente e futuro.O segundo, crítico ante os modelos dominantes, que "son o pueden ser insostenibles (crecimiento económico constante, consumismo)".O terceiro, transformativo, porque propicia consciência da transformação, bem como da responsabilização e capacitação que conduzem a estilos de vida, valores, comunidades e empresas mais sustentáveis. O quarto é o contextual, compreendendo que não há uma única forma de viver ou de negociar que se possa se considerar mais sustentável (UNESCO, 2012, p. 13).

A princípio, esses prismas denotam recorte e abordagem pertinentes. Mas este relatório de 2012 e o de 2014, bem como a Declaração de Aichi-Nagoya, não se aprofundam no contexto da ordem econômica, em suas contradições cada vez mais evidentes com o ambiente e a justiça social. Além disso, embora esses aspectos - integrador, crítico, transformativo e contextual - sejam consoantes com princípios da Educação Ambiental (EA), ao adotar o desafio da Educação para o Desenvolvimento Sustentável os textos da Unesco desconsideram o conceito de Educação Ambiental (EA) presente em diversos documentos internacionais, desde Tbilisi ${ }^{3}$, que foi uma conferência organizada pela Unesco e o PNUMA. Mesmo que a EA esteja presente em diversas iniciativas locais, citadas nos relatórios, os textos não se debruçam sobre as razões dessa mudança conceitual, mencionando, somente, que a EA seria um conceito mais restritivo. O conceito de EDS reuniria, portanto, uma diversidade de educações:

Temáticas educativas relacionadas con la EDS: educación ambiental, educación para la paz, educación sobre derechos humanos, educación de los consumidores, educación para el desarrollo, educación sanitaria, educación sobre el VIH y el SIDA, educación sobre biodiversidad, educación sobre cuestiones de género, educación inclusiva, educación multicultural, educación holística, educación mundial, educación para la ciudadanía, educación sobre reducción de riesgos de desastre, educación sobre el cambio climático y educación para la seguridad alimentaria (UNESCO, 2012, p. 18).

\footnotetext{
2 [...] adotam esta Declaração e exigem uma ação imediata para reforçar e ampliar a Educação para o Desenvolvimento Sustentável (EDS), a fim de habilitar as gerações atuais a satisfazer as suas necessidades, permitindo que as gerações futuras satisfaçam as suas próprias, com uma abordagem equilibrada e integrada quanto às dimensões econômica, social e ambiental do desenvolvimento sustentável. Esta Declaração reconhece que as pessoas estão no centro do desenvolvimento sustentável e se baseia nas realizações da Década da Educação para o Desenvolvimento Sustentável das Nações Unidas (2005-2014) (Tradução do autor).

${ }^{3}$ A Conferência Intergovernamental de Tbilisi (antiga União Soviética) é considerada, até os dias atuais, um dos principais eventos sobre Educação Ambiental, organizada pela Unesco e o Programa de Meio Ambiente da ONU - PNUMA, definindo que o processo educativo deve ser orientado para a resolução dos problemas concretos do meio ambiente, através de enfoques interdisciplinares e de participação ativa e responsável de cada indivíduo e da coletividade.
} 
Assim, os relatórios mencionados pressupõem que a dimensão econômica e social não estaria contemplada pela EA. Mas o documento da Conferência Intergovernamental de Tbilisi, organizado pela ONU (Unesco e Pnuma), em 1977, já atestava que a EA deve considerar a fauna e a flora, incluindo, também, os aspectos sociais, econômicos, científicos, tecnológicos, culturais, ecológicos e éticos (DIAS, 2000). Tanto assim que, no Brasil, a Política Nacional de Educação Ambiental - PNEA (Lei $\mathrm{n}^{\circ}$ 9.795/1999) define entre seus objetivos os "aspectos ecológicos, psicológicos, legais, políticos, sociais, econômicos, científicos, culturais e éticos" (BRASIL, 1999, s/p, grifos do autor).

\section{Sustentar esse desenvolvimento?}

O conceito de Desenvolvimento Sustentável projeta-se como meta dos processos educativos "holísticos e transformadores", mas é tratado superficialmente, sem que se aborde o seu caráter intrinsecamente controverso, para muitos uma "contradição em termos". Afinal, de que desenvolvimento se trata? Como o DS enfrenta o dilema da acumulação e do crescimento econômico - "[...] constante, consumismo" - que o são subjacente e que nas condições atuais, em grande parte do mundo, é causador de insustentabilidades? (UNESCO, 2012, s/p). Ora, não são os efeitos desse desenvolvimento que pautam o dilema da sustentabilidade desde a segunda metade do século XX, agravando-se até a atualidade? Será que o sistema econômico dominante é efetivamente capaz de satisfazer as necessidades presentes, assegurando as mesmas condições para as gerações futuras? Como educar sem discutir, ampla e profundamente, essas e outras questões correlatas?

Sato $(2008$, p. 3) questiona, desde a origem do conceito de Desenvolvimento Sustentável, que, se "o próprio relatório (Brundtland, 1987) anuncia que a definição de DS é controversa, não seria irresponsabilidade decretar uma década inteira dirigindo-se a educação para algo que nem se tem certeza do que seja?" Para Trajber $(2014$, p. 7$)$ "essa postura sobre o 'desenvolvimento' elimina diferenças sociais, mascara o conflito ideológico e mantém o capitalismo sob uma nova roupagem".

Em alguns textos, os relatórios descrevem uma noção de desenvolvimento (sustentável) como se fosse um consenso dado, revelando equívocos, como numa passagem do Relatório de 2012, onde se afirma que "apesar del crecimiento económico sin precedentes que se experimento em el siglo XX, la pobreza y la desigualdad (UNESCO, 2012, p. 10)" persistem. É uma afirmação estranha àquele prisma crítico, ensejando o falso dilema de que o crescimento vertiginoso deveria, por si mesmo, financiar o enfrentamento da pobreza e da desigualdade, como se a concentração de capital, a exploração do trabalho, a globalização dos mercados e seus monopólios, característicos desse sistema, não fossem indutores exatamente de injustiça social.

$\mathrm{Na}$ continuidade, o documento afirma que "los conflictos siguen poniendo de relieve la necesidad de forjar una cultura de paz (UNESCO,2012, p. 10). "Mas como forjar uma cultura de paz sem trazer à luz irracionalidades próprias de um mercado promotor de competitividade, fetiche, consumismo e individualismo?

O ser humano é senhor de suas ações, mas em condições historicamente dadas. Ou por outra, "os homens fazem a sua própria história, mas não a fazem segundo a sua livre vontade, em circunstâncias escolhidas por eles próprios, mas nas circunstâncias imediatamente encontradas, dadas e transmitidas (MARX, 1982, p. 417)". Dessa forma, cabe aos processos educativos críticos discutir vontades e circunstâncias.

A pobreza e a desigualdade-crescentes, segundo indicadores atuais, escancarados, por exemplo, pelo drama dos refugiados - podem ser vistas como uma das principais razões de conflitos e, portanto, de ausência de paz. O crescimento econômico, por seu turno, ainda mais sem precedentes não é contraditório com esse quadro de desigualdade, senão que gerador de 
pobreza e violência. Essa realidade ganha relevo no século $\mathrm{XX}$, e se torna ainda mais aguda no início do século XXI, com o fenômeno da globalização incitando, também, populações que fogem de violências, por fundamentalismos, ditaduras, injustiças sociais e econômicas, provocando ondas de refugiados. Ao mesmo tempo, persiste a escravidão por dívidas e as guerras sob argumento democrático e em defesa de direitos humanos, o que, por sua vez, atende ao incremento da produção bélica.

Como falar de sustentabilidade e justiça socioambiental sem enfrentar tais paradoxos?

Uma década voltada à educação para o DS, no mundo, deveria reconceituar esse objetivo com base no desafio da sustentabilidade, como propõe, por exemplo, Guimarães:

Afirmar que os seres humanos constituem o centro e a razão de ser do processo de desenvolvimento significa advogar um novo estilo de desenvolvimento que seja ambientalmente sustentável no acesso e no uso dos recursos naturais e na preservação da biodiversidade; socialmente sustentável na redução da pobreza e das desigualdades sociais e promotor da justiça e da equidade; culturalmente sustentável na conservação do sistema de valores, práticas e símbolos de identidade que, apesar de sua evolução e sua reatualização permanentes, determinam a integração nacional através dos tempos; politicamente sustentável ao aprofundar a democracia e garantir o acesso e a participação de todos nas decisões de ordem pública. Este novo estilo de desenvolvimento tem por norte uma nova ética do desenvolvimento, ética na qual os objetivos econômicos do progresso estão subordinados às leis de funcionamento dos sistemas naturais e aos critérios de respeito à dignidade humana e de melhoria da qualidade de vida das pessoas (GUIMARÃES, 2001, p. 55)

\section{Avanços da DEDS}

Os documentos da Unesco, incluindo a Declaração de Aichi, ressaltam como avanços obtidos nessa Década, maior prioridade observada em programas educativos nacionais e internacionais; melhora na compreensão conceitual da EDS; incremento de $34 \%$ na adoção da EDS, entre os anos de 2008 e 2012; 11,7 milhões de estudantes de 52 países envolvidos em programas de escolas ecológicas; 30 países com programas patrocinados por empresas, alcançando um investimento de 1,7 milhões de dólares/ano; 200 universidades assinando a Carta da Terra, subscrita pela Unesco, como marco ético.

Argumenta-se que sistemas educacionais passaram a trabalhar com a ideia do desenvolvimento sustentável e que agendas de educação e DS convergiram, ampliando compromissos locais crescentes. Em contextos não formais, a EDS estaria cada vez mais vinculada a iniciativas do setor privado. Será que se pode ver como promissora essa tendência, prevalecendo nesses setores a noção de que o valor da vida é superior ao valor da propriedade, onde se observe e se pratique a primazia da função social e ambiental, conforme dispositivo, por exemplo,da Constituição do Brasil, ainda pouco respeitado?

Uma lição aprendida, nessa década, destacada pelo relatório de 2014, é a de que liderança política forte é fator instrumental para avançar a EDS (UNESCO, 2014). Sem dúvida, sustentabilidade política está na base de processos de mudança nesse campo. Porém, a noção de liderança política precisa ser expandida para além de iniciativas circunscritas a governos que, muitas vezes, estão confortáveis em ação programática que não ameaça interesses econômicos que lhes dão sustentação. Liderança política deve ser vista no campo institucional e fora dele também, como nos movimentos sociais, ambientalistas, nas comunidades locais, nos instrumentos e mecanismos de democracia participativa, como conselhos participativos, nas conferências abertas, entre outros.

No entanto, poucas referências são encontradas sobre a evolução no campo político da EDS. No Brasil, por exemplo, mesmo com apoio da Unesco e do PNUMA, não é mencionado o avanço da política de educação ambiental, com a instalação do Órgão Gestor (MEC e 
MMA), nem tampouco o advento da Conferência Nacional de Meio Ambiente. Mereceria destaque, em especial, a Conferência Infantojuvenil pelo Meio Ambiente, que, em 4 edições nacionais e uma internacional, ao longo de 10 anos (2003/2013) envolveu mais de 20 milhões de pessoas, entre estudantes, professores e comunidades, e, em média, 14 mil escolas no país, por edição, discutindo e propondo estratégias em favor de uma EA focada num Brasil sustentável, com escolas sustentáveis (DINIZ, 2016, p. 39)

A Conferência Internacional Infantojuvenil Vamos Cuidar do Planeta (Confint), realizada em 2010, mobilizou 62 países, com participação de 47 desses até a Conferência final, realizada no Brasil. Um total de quase 90 mil escolas e mais de 13 milhões de pessoas participaram das discussões sobre as Mudanças Ambientais Globais, desde as conferências realizadas nas escolas (MEC, 2010).

Mas as referências restringiram-se, apenas, a iniciativas pontuais, como no caso da educação para a Economia Verde tratada na Rio+20, experiências em pesquisa sobre educação de crianças em ambientes naturais e uma iniciativa de Projeto Político Pedagógico em Osasco/SP, além da $6^{\text {a }}$. Conferência Internacional de Educação de Adultos - CONFITEA, em Belém/PA (2009) (UNESCO, 2014, p. 135 e 136).

Projetos e iniciativas mais abrangentes do Órgão Gestor/PNEA, como o V Congresso Ibero-americano de Educação Ambiental (Joinville, 2006), apoiado pelo PNUMA, por meio da Rede de Formação Ambiental da América Latina e Caribe, e as Diretrizes Curriculares Nacionais de EA, aprovadas pelo Conselho Nacional de Educação, em 2012, entre outros, muitos em parceria com a própria Unesco, inclusive no âmbito do Projeto de Cooperação Técnica com o Ministério do Meio Ambiente, não foram sequer listados nos relatórios da Unesco sobre a DEDS. Talvez, o reconhecimento dessa omissão tenha feito a organização da Conferência de Nagoya (2014) convidar o Departamento de Educação Ambiental do MMA a expor a sua experiência com os projetos Municípios Educadores Sustentáveis e Coletivos Educadores ${ }^{4}$.

\section{Desafios permanecem}

Segundo a diretora geral da Unesco, Irina Bokova, o desafio da sustentabilidade não se resolve com soluções econômicas e tecnológicas, regulações políticas ou incentivos financeiros. É preciso uma mudança fundamental que corresponda a uma nova maneira de pensar e agir. Por isso, a educação é o caminho mais poderoso para a sustentabilidade (UNESCO, 2014a, p. 16).

Agora, esse será um ponto de vista convergente com uma EA transformadora, de fato, quanto mais o processo educativo estiver calcado numa abordagem crítica, referenciada num olhar para a totalidade do sistema político, social e econômico, suas contradições e conflitos, de tal modo que a formação, comunicação e a mobilização socioambiental estejam orientadas para uma verdadeira emancipação social, cidadã.

A Declaração dos participantes da Conferência de Nagoya salienta (item 8) que a Educação para o Desenvolvimento Sustentável tem o potencial de capacitar estudantes a se transformar e à sociedade em que vivem, por meio de conhecimentos, habilidades, atitudes, competências e valores que sejam capazes de pautar uma cidadania global e desafios

\footnotetext{
${ }^{4} \mathrm{O}$ Coletivo Educador é a união de pessoas que trazem o apoio de suas instituições para um processo de atuação educacional em um território, [...] como grupo de profissionais que se aproximam para superar lacunas e dificuldades e potencializar as qualidades e capacidades de cada instituição, de cada pessoa, para possibilitar processos de educação ambiental permanentes, articulados, continuados e voltados a totalidade de habitantes de um determinado território. Constitui o núcleo de planejamento pedagógico de um amplo programa educacional e de desenvolvimento de processos formativos de formadores de educadoras(es) ambientais e seus grupos de Pesquisa-Ação Participante (FERRARO; SORRENTINO, 2005, p. 59-60).
} 
contextuais locais do presente e do futuro. Menciona o pensamento crítico e sistêmico, a criatividade e o trabalho em colaboração, bem como a interconectividade dos desafios globais e responsabilidades que emanam de tal consciência.

Mas é preciso ver como essa disposição se configura nas ações e nas políticas educativas locais. No Brasil, o que se vê nos anos recentes é que a política de sustentabilidade esteve restrita à área ambiental, rebaixada à condição de política setorial, com pouca ou nenhuma relevância no contexto da política econômica e do planejamento do estado. O Plano Nacional de Educação - Lei $N^{\circ} 13.005$, de 25 de junho de 2014) (BRASIL, 2014) ainda não contempla a EA, e o Órgão Gestor (MMA/MEC) da PNEA permanece sem apoio e com orçamento insuficiente.

Durante o VII Congresso Ibero-americano de Educação Ambiental, no Peru, foi proposto por educadores ambientais presentes, a criação de um fundo internacional de incentivo a sistemas nacionais de EA, o que poderia fortalecer iniciativas nacionais de educação para a sustentabilidade. Mas essa e outras propostas não foram acolhidas na declaração de Nagoya, que apenas faz um pedido, ao final, à diretora geral da Unesco, para que defenda a importância de garantir recursos adequados, incluindo o financiamento para EDS (UNESCO, 2014, p.2).

De fato, em diálogo com alguns educadores e especialistas brasileiros em EA, a impressão que permanece é que a década da EDS passou despercebida, causando estranheza que um movimento dessa envergadura não tenha produzido ressonância significativa. Possivelmente, em outros países, como os árabes, tenha obtido maior atenção, em vista da importância crucial do tema diante da realidade local.

Para alguns, apesar disso, a Unesco no Brasil é parceira relevante no debate socioambiental. Ainda que o poder de transformação seja insuficiente nessas instituições internacionais. Alguns educadores entendem que a EDS tem sido particularmente importante na parte mais rica e desenvolvida do mundo, em virtude de se observar uma maior pegada ecológica.

Diante das previsões do IPCC (2007), segundo as quais as perspectivas para os próximos 100 anos estão entre o pior e o menos pior, somadas ao fato de que $20 \%$ do contingente mais rico da população mundial são responsáveis por $86 \%$ de todo consumo privado, de tal modo que um norte-americano, em média, impacta o equivalente a cerca de 10 africanos ou asiáticos. Educadores ambientais, no Brasil, parecem ter pouca esperança de que essa década tenha realmente feito diferença suficiente à inflexão necessária no contexto político, econômico, social e ambiental do Brasil e do mundo.

\section{Não Ditos na DEDS: sinais de mudança?}

No preâmbulo dos princípios do Tratado Internacional de Educação Ambiental para Sociedades Sustentáveis e Responsabilidade Global', afirma-se que "a EA não é neutra, mas ideológica. É um ato político" (Fórum Internacional de ONGs, 1992, p. 195). Apesar de algumas controvérsias, na ocasião, esse princípio se assenta nas ideias de Paulo Freire, quando afirma que a educação sozinha não muda a sociedade, mas que ela integra, necessariamente, um projeto de transformação. $O$ tratado explica que essa transformação reitera a necessidade de mudanças diante da natureza sistêmica das crises que ameaçam o futuro da humanidade, de uma "revisão da história dos povos nativos para modificar enfoques etnocêntricos", valorizando a diversidade cultural, linguística e ecológica, incluindo diferentes formas de conhecimento, contra a lógica capitalista de patenteamento ou de monopólio. $\mathrm{O}$

\footnotetext{
${ }^{5} \mathrm{O}$ Tratado foi discutido e aprovado por representações da sociedade civil mundial, durante a I Jornada de Educação Ambiental, aberta por Paulo Freire, no Fórum Global da Rio-1992 (Fórum Internacional de ONGs), paralelamente à Conferência Mundial da ONU sobre Meio Ambiente e Desenvolvimento - UNCED.
} 
tratado não tangencia os conflitos e propõe que se trabalhe de maneira justa e humana, democratizando os meios de comunicação de massa.

São aspectos que deveriam ter sido aprofundados com as experiências relatadas e qualificados nos documentos da Unesco, desenhando, por conseguinte, alguns caminhos para as transformações a serem apoiadas pelos processos educativos, em todo o mundo.

O economista alemão Reinhard Loske (2015), por exemplo, critica mais amplamente a política ambiental que não vem alterando a estrutura do sistema econômico. Admite que algumas sociedades se tornaram mais limpas, o que não quer dizer mais sustentáveis. Prova disso é o uso de recursos, o consumo de energia, a ocupação da terra e a emissão de gases de efeito estufa, que permanecem extremamente altos, denunciando uma equação paradoxal: os países ricos são os mais limpos e, ao mesmo tempo, os menos sustentáveis.

Consoante com a proposta de Bokova (UNESCO, 2014a), Loske propõe uma guinada no pensamento e na prática. Mas vai além, ao explicar que a lógica de crescimento do capital prega ganhos em eficiência que, na verdade, são consumidos por sua expansão, gerando pouco ganho para a natureza, fonte de matéria prima. Assim, a sociedade industrial capitalista, por si mesma, não possui a capacidade de gerar estratégias de sustentabilidade satisfatórias.

Ainda assim, Loske (2015) identifica nichos de pioneirismos e de ação em favor de mudanças relativamente novas, incentivados por um novo caráter dos conflitos. Segundo seu ponto de vista, a postura contra o sistema derivou para uma posição mais expressiva em favor de mudanças. Por exemplo, dá-se maior ênfase para as energias renováveis, do que contra as usinas nucleares, mais alimentação orgânica do que contra agrotóxicos, menos contra os automóveis e mais em favor da mobilidade sustentável.

Com base nisso, descreve 5 conceitos-chave para essas ações políticas proativas:

Economia do compartilhamento (sharing economy): compartilhar e utilizar coletivamente os bens;

Economia da vida útil longa (repair economy): aumentar a duração da vida útil dos produtos e aprimorar a reparabilidade dos bens de uso;

Economia do prossumidor (prosumer economy): reintegrar produção e consumo;

Economia da subsidiariedade (regional economy): preferência por produção regional e descentralizada e regulamentação com orientação sustentável dos fluxos internacionais de bens - desglobalização); e

Economia da resiliência (resilient economy): como se pode reduzir a dependência da economia em relação ao suprimento externo de recursos e ao crescimento permanente e fortalecer sua capacidade de resistência a distúrbios (LOSKE, 2015, p. 12).

\section{O Papa e as cúpulas ineficazes}

Em artigo no jornal Folha de São Paulo (13/07/15), Ricardo Melo lembrou alguns passivos históricos atribuídos ao Vaticano, como a aproximação com o nazismo, o luxo do Vaticano em contraste com a pobreza pelo planeta, os casos de pedofilia, entre outros, para, na verdade, ressaltar algumas falas recentes do Papa Francisco, que chamaram a atenção da mídia e de seus fiéis. "Quando o capital se converte em ídolo, arruína a sociedade, destrói a fraternidade, povos enfrentam povos". Ou quando caracterizou o capitalismo como uma "ditadura sutil", na fronteira da democratização. Em relação ao consumismo, propôs uma redução no ritmo da produção e do consumo na perspectiva de outro desenvolvimento (MELO, 2015, p. A6)

Pode-se dizer que são meras expressões de valores, em parte coerentes com a doutrina cristã, mas sem compromisso com a vida prática, cotidiana, e que apenas servem para isentar o pontífice e o Vaticano de vicissitudes e controvérsias que envolvam o sistema econômico dominante no mundo. Mas o mesmo Papa dedicou-se, no início ainda de seu pontificado, a 
lançar a Encíclica Louvado Seja, sobre o Cuidado com a Casa Comum (FRANCISCO, 2015), recolhendo e organizando diagnósticos e manifestações de organizações de bispos de diversas localidades do mundo, como a Confederação Nacional dos Bispos do Brasil - CNBB.

Nela, Francisco começa agradecendo a todos aqueles que lutam contra a degradação ambiental na vida dos mais pobres. Reconhece que cuidar e melhorar o mundo depende de mudanças nas estruturas consolidadas de poder, e aponta entre as principais dificuldades deste intento a negação do problema, a indiferença, a resignação acomodada ou a confiança cega nas soluções técnicas. Segundo afirma, tecnologia e finanças trabalham com solução única, sendo incapazes de perceber "o mistério das múltiplas relações". Ao buscar a solução de um problema, por vezes, criam outros (FRANCISCO, 2015, p. 20).

O Papa diz que "preocupa a fraqueza da reação política internacional. A submissão da política à tecnologia e à economia demonstra-se na falência das cúpulas mundiais sobre o meio ambiente". Quanto à declaração final da Rio+20, a Encíclica é direta: "extensa mas ineficaz" (FRANCISCO, 2015, p. 38).

Outro tema citado é a gestão das águas, que enfrenta uma tendência retrógrada de privatização, colocando em risco um direito essencial, condição básica ao atendimento de outros direitos humanos. Isso porque há uma espécie de divinização do mercado, incapacitado para a defesa do ambiente, especialmente pelo princípio da subordinação da propriedade privada. Incisivo, Francisco afirma que a técnica não é neutra, respondendo, muitas vezes, a interesses de grupos de poder.

"Há demasiados interesses particulares e, com muita facilidade, o interesse econômico chega a prevalecer sobre o bem comum e manipular a informação para não ver afetados os seus projetos" (FRANCISCO, 2015, p. 38). Trata-se de um reflexo da perda de poder dos estados nacionais diante do poder econômico e financeiro transnacional.

O tema controverso dos cereais transgênicos é alvo de silêncio nos documentos multilaterais, enquanto nesta Laudato $S i$ é tratado como associado, em geral, à concentração de terras produtivas com o "progressivo desaparecimento de pequenos produtores [...]" (FRANCISCO, 2015, p. 84).

Diante de todo esse contexto de crise, conclui por um necessário e corajoso avanço rumo a uma grande revolução cultural, com destaque para o caminho educativo.

Sobre a educação ambiental, como uma nova maneira de ver a vida, bem como a sociedade em sua relação com a natureza, Francisco avalia que ampliou seus objetivos muito além da informação científica e da conscientização e prevenção de riscos. Na atualidade, a EA inclui a crítica de mitos da modernidade, como o individualismo, o progresso ilimitado e o mercado desregrado. Quanto à crise ecológica, defende-se que as soluções não virão "de uma única maneira de interpretar e transformar a realidade. É necessário recorrer também às diversas riquezas culturais dos povos, à arte e à poesia, à vida interior e à espiritualidade" (FRANCISCO, 2015, p. 43).

Parece pertinente citar essa ação da cúpula da Igreja Católica, por sua importância em iniciativas de educação em todo o mundo, seja no contexto da evangelização, seja no âmbito de sistemas de ensinos de diversos países, em especial o Brasil e toda a América Latina. Além disso, trata-se de uma manifestação de alta relevância internacional, em virtude da liderança reconhecida de um Papa, ainda mais quando contrasta em seu conteúdo, de maneira flagrante, com o tom insípido da maioria dos textos consensuais de agências multilaterais, como a ONU.

Há de se reconhecer que esse documento, a despeito de passivos históricos da Igreja, expressa corajosamente valores e propósitos de vanguarda, diferente da tendência atual reacionária em diversos países. A ponto de o articulista Ricardo Melo concluir seu artigo dizendo que, no Brasil, o Papa "provavelmente estaria sujeito a pedido de impeachment ou de recontagem de votos dos cardeais que o elegeram" (MELO, 2015, p. A6). 


\section{Conclusão}

A menção à Encíclica, às ideias do economista Loske e ao Tratado Internacional de Educação Ambiental busca demonstrar, em contraste, lacunas e insuficiências dos relatórios e debates descritos sobre essa DEDS. Apesar disso, um mérito a ser reconhecido da Conferência de Nagoya foi ter declarado a continuidade do processo, lançando novos desafios. Este artigo tem a intenção também de colaborar com as discussões a seguir.

Essa é uma exigência da conjuntura decorrente à DEDS, que parece ainda mais desafiadora. São dilemas e contradições que precisam ser enfrentados por todas as correntes, especialmente pela chamada Educação Ambiental Crítica, que se propõe avistar a totalidade dos processos, com uma estratégia capaz de convergir forças políticas, transversalizar políticas públicas e mobilizar o conjunto da sociedade, sobretudo as camadas mais atingidas pela crise socioambiental. Tudo em favor de uma agenda de mudança.

Para essa agenda, durante a Assembleia do International Council for Adult Education - ICAE $(2007)^{6}$, Boaventura de Sousa Santos apontava uma iniciativa historicamente necessária, no Brasil. A pergunta do sociólogo português era porque os movimentos indígenas, sem-terra e atingidos por barragem ainda não desenvolveram uma estratégia sinérgica. Na atualidade, poderiam se articular também com agricultores familiares, produtores orgânicos, movimentos de sem-teto, além de catadores de materiais recicláveis. Essa convergência potencializaria cada um desses segmentos que, isolados, se mantém vulneráveis.

A exemplo dos seringueiros, castanheiros, quebradeiras de coco e grupos indígenas que, nos anos de 1980, se uniram em torno da Aliança dos Povos da Floresta, também os segmentos citados possuem uma pauta de demandas tão associada à agenda socioambiental, quanto de confronto com o modelo de desenvolvimento dominante.

A crise hídrica e climática no Brasil, por suposto, integraria essa agenda, reivindicando-se mudanças radicais na gestão das águas, bem como ante os riscos de desastres ambientais, como no caso do maior acidente socioambiental registrado no país, ocorrido em 2015, na região de Mariana, em Minas Gerais, com passivos e prejuízos para a sociedade ainda em aberto.

Esse quadro deve ser visto no contexto do modo de se desenvolver em curso, da mesma maneira que o genocídio contra os Guaranis Caiowás, no Mato Grosso do Sul. Em debate recente, em São Paulo/SP ${ }^{7}$, o mesmo Boaventura denunciava esse fato, lembrando, ironicamente, que, para representantes do agronegócio local, tal violência pode ser justificada como um direito ao desenvolvimento, sendo os índios um obstáculo. Como se pode ver sustentabilidade nesse modelo?

Parece evidente que, diante desses dilemas, o momento exige criatividade, reflexão e ação, ecumenismo, formação de novas e jovens lideranças, valorização de nichos e núcleos de inovação social, econômica e política, requalificando a participação com o fortalecimento da democracia participativa, como fonte de revitalização de sua combalida expressão representativa, no âmbito de uma nova cultura democrática.

O Papa Francisco conclama educadores e educadoras ambientais que, no Brasil e no mundo, têm função mobilizadora e formativa por essa cultura, superando limites da educação

\footnotetext{
${ }^{6}$ Moema Viezzer, Coordenadora do Programa de Educação Popular Ambiental do ICAE, por ocasião da ECO92, Miriam Duallibi, Coordenadora do Instituto Ecoar pela Cidadania, de São Paulo, e o autor participaram desta Assembléia do ICAE e do debate com Boaventura de Sousa Santos, além de apresentarem o Tratado Internacional de Educação Ambiental para Sociedades Sustentáveis e Responsabilidade Global. Mais informações, ver http://www.icae.org.uy/eng/voices211.pdf (Acesso em 02 set 2016)

7 Mesa de Debates Boaventura e os Movimentos Sociais no Brasil, Teatro da Universidade Católica TUCA/PUC-SP, em 28/10/2015. Ver https://www.youtube.com/watch?v=SBrAm37dO8s (Acesso em 02 Set 2016)
} 
para o desenvolvimento sustentável, que parece incapaz de enfrentar as contradições em questão. Em seu alerta, o Papa afirma que quanto mais "vazio o coração da pessoa", mais objetos busca-se adquirir e consumir (FRANCISCO, 2015, p. 122)

Loske (2015, p. 20) por sua vez, diz que diferente da lógica competitiva, produtivista e consumista ou de uma perspectiva egoísta ou idealista, quando a "'(pre)ocupação consigo mesmo' e 'preocupação com o mundo como todo' se unem", a atuação pela mudança tende a conquistar efeito mais significativo".

Nesse mesmo sentido, Paulo Freire avalia que "não há diálogo [...] se não há um profundo amor ao mundo e aos homens. Não é possível a pronúncia do mundo, que é um ato de criação e recriação, se não há amor que o funda [...]. Sendo fundamento do diálogo, o amor é, também, diálogo" (FREIRE, 1987, p. 79-80).

Somados também aos bons acúmulos e experiências colhidos nessa década da Unesco, os princípios e iniciativas descritos acima podem contribuir, significativamente, por uma nova maneira de pensar e de fazer a educação, sempre em favor das transformações necessárias rumo a sociedades justas e sustentáveis.

\section{Referências}

BRASIL. Lei 9.795, de 27 de abril de 1999. Dispõe sobre a educação ambiental, institui a Política Nacional de Educação Ambiental e dá outras providências. Brasília: Casa Civil. Disponível em: <http://www.planalto.gov.br/ccivil_03/leis/L9795.htm>. Acesso em 31 ago. 2016.

BRASIL. Plano Nacional de Educação (PNE) 2014-2024: Lei no 13.005, de 25 de junho de 2014, que aprova o Plano Nacional de Educação (PNE) e dá outras providências. - Brasília: Câmara dos

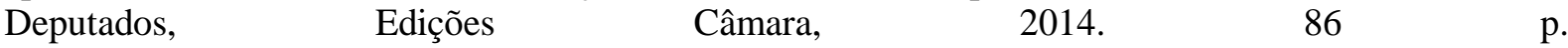
http://www.observatoriodopne.org.br/uploads/reference/file/439/documento-referencia.pdf (Acesso em 02 set. 2016)

DIAS, G. F. Educação Ambiental: princípios e práticas. São Paulo: Gaia, 2000.

DINIZ, N. S. M. Documento técnico contendo 02 cadernos que integrarão o "Material educativo sobre os 10 (dez) anos das Conferências Infantojuvenis pelo Meio Ambiente", abordando o histórico, os resultados das CNIJMA em números e as metodologias do processo. Produto 1. Projeto BRA/IICA/09/005. Contrato 116110. Brasília: 2016

FERRARO, L. A.; SORRENTINO, M. Coletivos Educadores. In: FERRARO, L. A. (Coord.): Encontros e Caminhos: Formação de Educadoras(es) Ambientais e Coletivos Educadores - Brasília: MMA/DEA, 2005. p.57-69.

FRANCISCO, Papa. Laudato Si, o cuidado da casa comum. Brasília: Edições CNBB, 2015

FREIRE, P. Pedagogia do Oprimido. Ed. Rio de Janeiro: Paz e Terra, 1987.

GUIMARÃES, R. P. A Ética da Sustentabilidade e a Formulação de Políticas de Desenvolvimento. In: DINIZ, N.; SILVA, M.;VIANA, G. (Orgs.). O Desafio da Sustentabilidade: um Debate Socioambiental no Brasil. São Paulo. Ed. Fundação Perseu Abramo, 2001. p. 43-71

IPCC: Climate Change 2007: Impacts, Adaptation and Vulnerability. Contribution of Working Group II to the Fourth Assessment Report of the Intergovernmental Panel on Climate Change, M.L. Parry, O.F. Canziani, J.P. Palutikof, P.J. van der Linden and C.E. Hanson, Eds., Cambridge University Press, Cambridge, UK, 976pp. 
LOSKE, R. Novas formas de economia cooperativa como contribuição para o desenvolvimento sustentável. Reflexões sobre a reinserção da economia na sociedade e na natureza. Tradução de Théo Amon. Rio de Janeiro: Fundação Heinrich Böll, 2015. Disponível em:<http://br.boell.org>. Acesso em:31 ago. 2016.

MARX, K. O 18 de Brumário de Louis Bonaparte. In: ENGELS, F.Obras escolhidas. Moscou: Progresso, 1982.

MEC, Relatório Final da Conferência Internacional Infantojuvenil pelo Meio Ambiente, Vamos Cuidar do Planeta, CONFINT. Ministério da Educação. Ministério do Meio Ambiente. Brasília, 2010.

MELO, Ricardo. Até o Papa Percebe. Artigo no jornal Folha de São Paulo. São Paulo, p. A6. 13 Jul 2015.

Organização das Nações Unidas para a Educação, a Ciência e a Cultura - UNESCO. Forjar la Educación del Mañana. Decenio de las Naciones Unidas de la Educación para el Desarrollo Sostenible - Informe 2012 (abreviado). Paris, França. 2012

Organização das Nações Unidas para a Educação, a Ciência e a Cultura - UNESCO. Declaração de Aichi-Nagoya. In: CONFERÊNCIA MUNDIAL SOBRE EDUCAÇÃO PARA O DESENVOLVIMENTO SUSTENTÁVEL, Aichi-Nagoya, 2014.Disponívelem: <http://www.unesco.org/new/fileadmin/MULTIMEDIA/HQ/ERI/pdf/AichiNagoya_Declaration_EN.pdf>. Aichi-Nagoya: UNESCO, 2014. Acessoem:8 ago. 2016.

Organização das Nações Unidas para a Educação, a Ciência e a Cultura - UNESCO. Shaping the Future We Want. UN Decade of Education for Sustainable Development (2005-2014) -Paris: UNESCO, 2014a. (Final Report).

PORTAL EDUCAÇÃO - Cursos Online: mais de 1000 cursos online com certificado. Disponível: <http://www.portaleducacao.com.br/biologia/artigos/27425/conferencia-de-tbilisi1977\#ixzz4G71IUmnu>.Acesso em: 8 ago. 2016.

SATO, M. Em busca de sociedades sustentáveis. Pátio - Revista Pedagógica: Educação para o desenvolvimento sustentável, Porto Alegre, ano XII, p. 55-59, Mai./Jul., 2008.

TRAJBER,R. Estudo analítico sobre as políticas públicas de educação com relação às mudanças climáticas, sustentabilidade e prevenção de desastres no Brasil. São José dos Campos: Unesco Cemaden/MCTI, 2014. 43 p. Relatório Técnico elaborado no âmbito do Projeto 914BRZ2018 (Edital Seped 83/2013 - Produto 1).

TRATADO Internacional de Educação Ambiental para Sociedades Sustentáveis e Responsabilidade Global. Fórum Internacional de ONGs. Tratado das ONGs, Aprovados no Fórum Global ECO-92. Santos/SP, 1992. 264 p. 